\title{
Estudo de caso das patologias de um reservatório por meio do uso de VANT
}

\author{
$\underline{\text { V. N. V. Tinoco }}^{1 *}$, R. T. V. Fernandes ${ }^{2}$, J. M. M. Gurgel, B. D. A. da Silveira ${ }^{3}$, A. M. de Sousa \\ Junior $^{4}$ \\ *Vinícius Navarro Varela Tinoco: navarrotinoco@gmail.com \\ ${ }^{1}$ Programa de Pós-Graduação em Engenharia Civil, Universidade Federal de São Carlos, São Carlos, Brasil \\ ${ }^{2}$ Departamento de Ciências Animais, Universidade Federal Rural do Semiárido, Mossoró, Brasil \\ ${ }^{3}$ Departamento de Engenharias, Universidade Federal Rural do Semiárido, Caraúbas, Brasil \\ ${ }^{4}$ Departamento de Engenharia e Ciências Ambientais, Universidade Federal Rural do Semiárido, Mossoró, Brasil
}

\begin{abstract}
RESUMO
O presente trabalho apresenta uma metodologia do uso de drones para análise de edificações com o objetivo de identificar manifestações patológicas, por meio de um estudo de caso de um reservatório de água. Foi realizada uma parametrização das diferentes estruturas do reservatório e, com o auxílio do drone, foram capturadas imagens das manifestações identificadas visualmente. Os resultados mostraram com detalhes o estado de deterioração externa do reservatório estudado e percebeu-se a aplicabilidade do uso dos drones quanto à vistoria de locais de difícil acesso. Concluiu-se que a utilização da metodologia da inspeção remota pode ser essencial para a segurança física dos profissionais de engenharia, comprovando sua eficácia. Foram apontadas possíveis causas para as manifestações patológicas e indicadas técnicas de recuperação da estrutura.
\end{abstract}

Palavras chave: controle de qualidade; patologias em reservatórios; concreto armado; Aeronave Remotamente Tripulada.

\section{INTRODUÇÃO}

A construção de edificações para diversos fins é uma preocupação desde os primórdios da humanidade. $\mathrm{O}$ crescimento da construção civil aliado à necessidade de novas estruturas trouxe conhecimento e estudos sobre estruturas e materiais. Porém, assim como parte do processo do avanço das ciências e do conhecimento, ainda existem imperfeições nos processos construtivos a serem estudadas e superadas.

O crescimento acelerado das cidades e consequente desenvolvimento do ramo da construção civil resultaram em um avanço tecnológico no campo das técnicas e dos materiais de construção, entretanto Silva, Pimentel e Barbosa (2003) apontam que foi observado um grande número de edificações apresentando manifestações patológicas, inclusive edificações relativamente novas. Com o crescimento urbano, surge a necessidade da criação planejada de infraestrutura básica para atender as necessidades das populações como saneamento, energia, estradas e espaços para educação, saúde, lazer, entre outros. Para atender a necessidade de água encanada, empresas especializadas instalam reservatórios espalhados pela cidade para servidão de determinadas áreas. As manifestações patológicas que aparecem com maior assiduidade de acordo com Roscoe (2008) são: corrosão em armaduras de concreto, destacamentos, bolor (mofo), eflorescência e fissuras. 
O presente trabalho almeja realizar um estudo de caso de forma a identificar as manifestações patológicas mais frequentes em reservatórios por meio do uso de veículo aéreo não tripulado VANT.

\section{REVISÃO BIBLIOGRÁFICA}

\subsection{USO DE DRONE}

A obtenção de imagens em alturas já é uma realidade. Desde filmes e documentários até trabalhos de fiscalização e investigação criminal recebem o apoio de imagens aéreas. Estas imagens podem ser obtidas com auxílio drones. Essas máquinas são vantajosas para esse tipo de atividade pois permitem o acoplamento de câmeras (sejam térmicas ou de alta definição) para visualização remota, têm voo estável e possuem a capacidade de se manterem relativamente estáticos quando comparados a outros tipos de aeronaves de pequeno porte.

De acordo com a ANAC (Agência Nacional de Aviação Civil), o uso de RPA's (aeronaves remotamente pilotadas) ou drones, como são popularmente chamados, é permitido para atividades profissionais sob condições impostas pelo Regulamento Brasileiro de Aviação Civil Especial n ${ }^{\circ}$ 94/2017, pelo DECEA (Departamento de Controle de Espaço Aéreo) e pela ANATEL (Agência Nacional de Telecomunicações). A ANAC determina que os drones só podem ser operados à uma distância mínima de 30 metros horizontais daqueles que não estejam envolvidos na operação. As RPA's são divididas em 3 classes de acordo com seu peso: classe 3 , até 25 quilogramas; classe 2, de 25 a 150 quilogramas; e classe 1, mais de 150 quilogramas. Os documentos necessários para voos com aeronaves acima de 250 gramas são a certidão de cadastro do equipamento, certificado de aeronavegabilidade válido (para aeronaves não tripuladas de Classes 1 e 2 e as de Classe 3 que voem acima de 400 pés), manual de voo, apólice de seguro, documento com avaliação de risco, licença e habilitação de piloto válidas para operações acima de 400 pés em relação ao nível do solo ou que atuarem em operações de RPA's Classe 1 e 2 e extrato do Certificado Médico Aeronáutico para pilotos de aeronaves não tripuladas da Classe 1 ou 2. De acordo com o DECEA, é necessário ainda uma Autorização de Voo do Ministério da Defesa para aerolevantamentos.

\subsection{PATOLOGIAS}

Souza e Ripper (1998) apontam que ao se tratar da área da construção civil, patologias ou manifestações patológicas são objeto de estudo pois podem resultar desde em um problema na saúde dos usuários da mesma até o encurtamento da vida útil de uma edificação ou sua inutilização total. São resultados do envelhecimento natural da estrutura, das falhas humanas no processo construtivo ou de erros em alguma fase de planejamento do projeto. $O$ fato de que patologias estruturais comprometem a utilidade de uma obra demandando recursos financeiros, faz com que os ramos da construção civil especializados em vistorias prediais e manutenção sejam necessários. A vida útil, a segurança, a confiabilidade e o risco dos sistemas de infraestrutura civil tornaram-se questões emergentes nos últimos anos devido às catástrofes naturais e humanas, questões de sustentabilidade e ao aquecimento global.

\subsection{INVESTIGAÇÃO COM DRONE}

Fernandes et al (2021) apresenta o uso do VANT como uma forma eficiente de identificação de manifestações patológicas de forma remota em seu estudo. Apesar das vias pavimentadas não serem um local de difícil acesso, como seriam pontes ou reservatórios elevados, a 
eficiência do uso de fotos feitas de forma remota é comprovada pela comparação entre a identificação e mensuração de manifestações realizadas de forma direta, ou seja, no próprio local do estudo, e da maneira alternativa, pelo uso do drone, obtendo 94,4\% de acerto.

Enquanto as vias possuem fácil acesso, locais em altura devem recorrer o profissional de engenharia ao risco para poder realizar inspeções. Os VANTs podem voar automaticamente ou ser pilotado por meios eletrônicos e computacionais e se apresentam como alternativa a esta problemática, pois apesar de idealizados para fins militares, utilizados inicialmente em missões muito perigosas para serem executadas por seres humanos, vêm ganhando destaque entre intervenções civis com aplicações desde a fiscalização de obras, até a inspeção de estruturas em ambientes de alto risco (Melo, 2016).

Bhonge et al (2020) apresenta a possibilidade da inspeção de pontes por uso de drones comerciais. Ele reforça a metodologia dizendo que a inspeção tradicional com equipamentos de rapel associada à ensaios físicos não são necessários a partir do momento que a inspeção remota já é suficiente para se chegar à uma conclusão que leve à interdição da estrutura em questão, sendo então, no caso da metodologia apresentada, a primeira parte de uma inspeção de locais de difícil acesso e condicionante à continuação ou não de uma investigação mais aprofundada.

\section{METODOLOGIA DA PESQUISA}

Para análise e identificação das manifestações patológicas, a obra foi dividida em vistas arbitrárias referentes aos pilares de sustentação da mesma, sendo 12 vistas. O primeiro pilar aponta para Sudoeste (em direção ao limitante do terreno entre o reservatório e a UFERSA), e as outras sendo enumeradas em sentido horário, como apresentado na Figura 1.

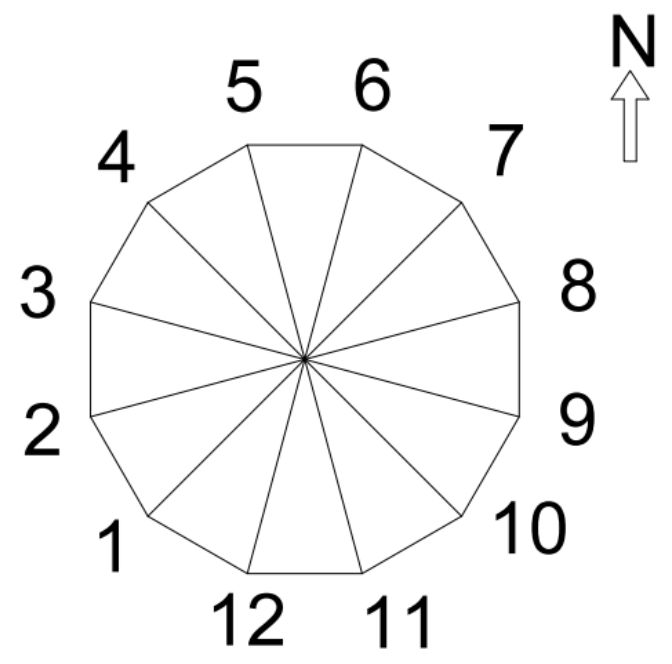

Figura 1. Numeração dos pilares. Fonte: Autoria própria (2021).

Cada vista foi dividida em inferior, com foco nos pilares, e superior, focando nas vigas que sustentam o reservatório e nas lajes entre estas, como indicado na Figura 2. 


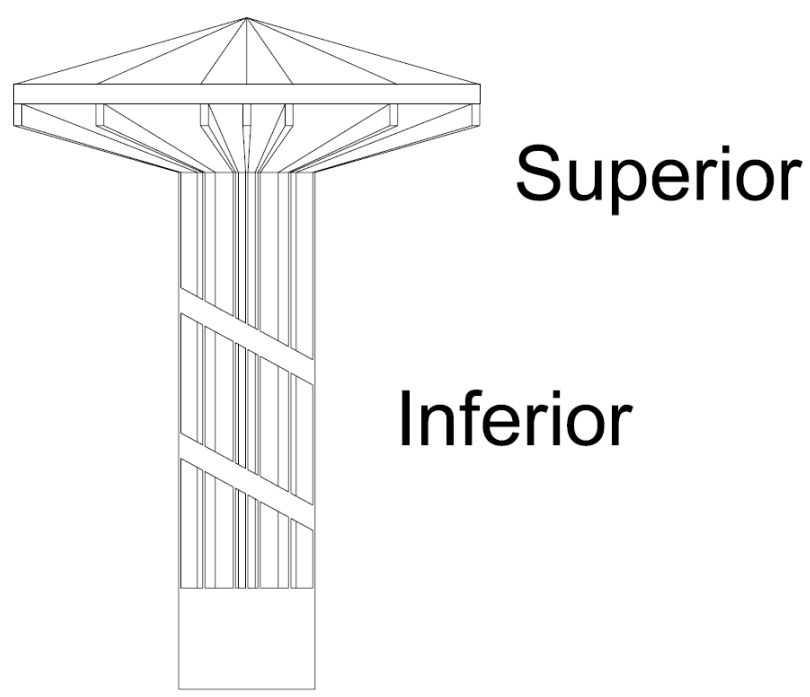

Figura 2. Parametrização das vistas. Fonte: Autoria própria (2021).

Para análise dos elementos estruturais, a inspeção visual foi feita através da captura de fotos pelo drone DJI PHANTOM 4 PRO controlado remotamente com câmera.

\subsection{DESCRIÇÃO DA ÁREA DE ESTUDO}

O objeto do estudo é o Reservatório da Companhia de Águas e Esgotos do Rio Grande do Norte (CAERN), localizado no bairro Costa e Silva, ao lado da UFERSA, em Mossoró, Rio Grande do Norte. A construção encontra-se a céu aberto, por ser um reservatório de água de grande porte. Sofre influência do calor e radiação solar praticamente o ano inteiro.

\subsection{MÉTODO DE ESTUDO ADOTADO: INSPEÇÃO VISUAL}

A inspeção visual é feita objetivando detectar sintomas de degradação e defeitos, identificando origem e potenciais de problemas e má utilização. Para realiza-la, usualmente, leva-se em consideração alguns parâmetros: verificação de informações obtidas durante o planejamento da avaliação; pinturas e proteções antigas; aparência da superfície original do concreto (ou aço); diferenças de coloração do concreto (ou aço); presença de fissuras, suas aparências e morfologias; deterioração superficial da camada inicial do concreto (ou aço); deterioração do material em si (concreto ou aço); armadura exposta; deformações da estrutura; presença de umidade ou água; presença de vazamentos ou deteriorações em equipamentos.

Atualmente utilizam bastante a inspeção visual remota e de acordo com a ANAC, o uso de RPA's ou drones, como são popularmente chamados, é permitido para atividades profissionais sob condições impostas pelo Regulamento Brasileiro de Aviação Civil Especial no 94/2017, pelo DECEA e pela ANATEL.

Como um dos objetivos da presente metodologia, busca-se dispensar demais análises físicas por outros meios pela detecção de manifestações patológicas pelo uso do drone. No caso de mais análises serem necessárias, estas serão indicada como resultado da presente metodologia, que se insere no contexto de avaliação inicial e principal de estruturas de concreto armado de difícil acesso.

\section{RESULTADOS E DISCUSSÕES}


A deterioração foi localizada em muitas partes da estrutura e as manchas de umidade são facilmente visíveis pois contrastam fortemente nos pilares, nas vigas de sustentação e nas lajes do reservatório elevado. A umidade em excesso facilita a ação de agentes orgânicos como microrganismos responsáveis pela proliferação de fungo e bolor. Por tratar-se de uma estrutura com a finalidade de armazenar água, sua impermeabilização interna deve estar sempre em boas condições. A umidade que se dá por meio da permeabilidade do concreto pode afetar negativamente a estruturas em vários aspectos. Essa umidade serve como fixador do gás carbônico (CO2) da atmosfera no interior da estrutura, podendo acarretar no aumento da carbonatação, que quando ocorre de forma muito intensa, pode gerar fissuras internas e o desplacamento observado. Esta também pode causar a corrosão das armaduras, inviabilizando toda uma seção do concreto. A Figura 3 apresenta uma a visualização da estrutura para quem se encontra no nível térreo observando a mesma.

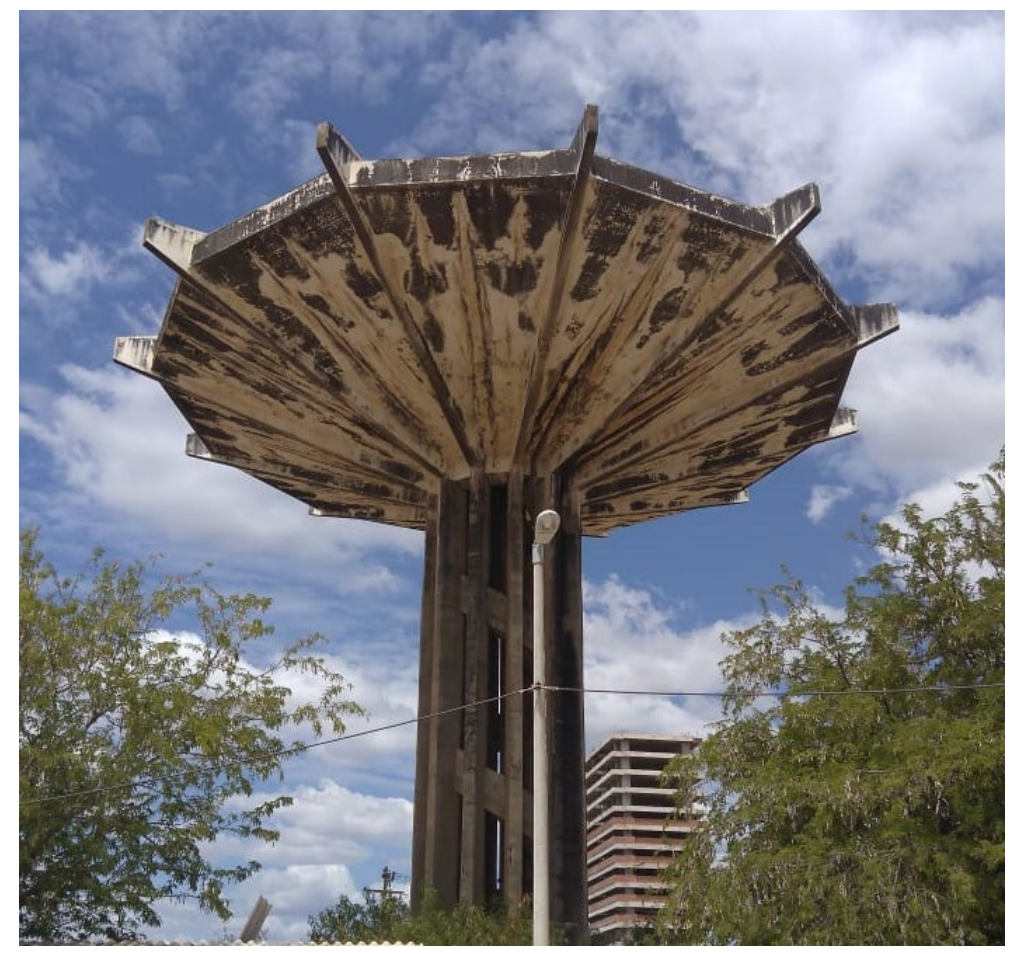

Figura 3. Reservatório, objeto do estudo. Fonte: Arquivo da pesquisa (2021).

Por meio da inspeção visual, detectou-se ferragens expostas nos pilares causados pelo desplacamento do concreto armado. Essa manifestação patológica foi identificada nos pilares numerados 1, 2, 5, 6, 7, 8, 10,11 e 12. Por estarem sob constante intemperismo, as armaduras expostas apresentavam sinais de oxidação e corrosão, como pode ser observado no mosaico da Figura 4. 


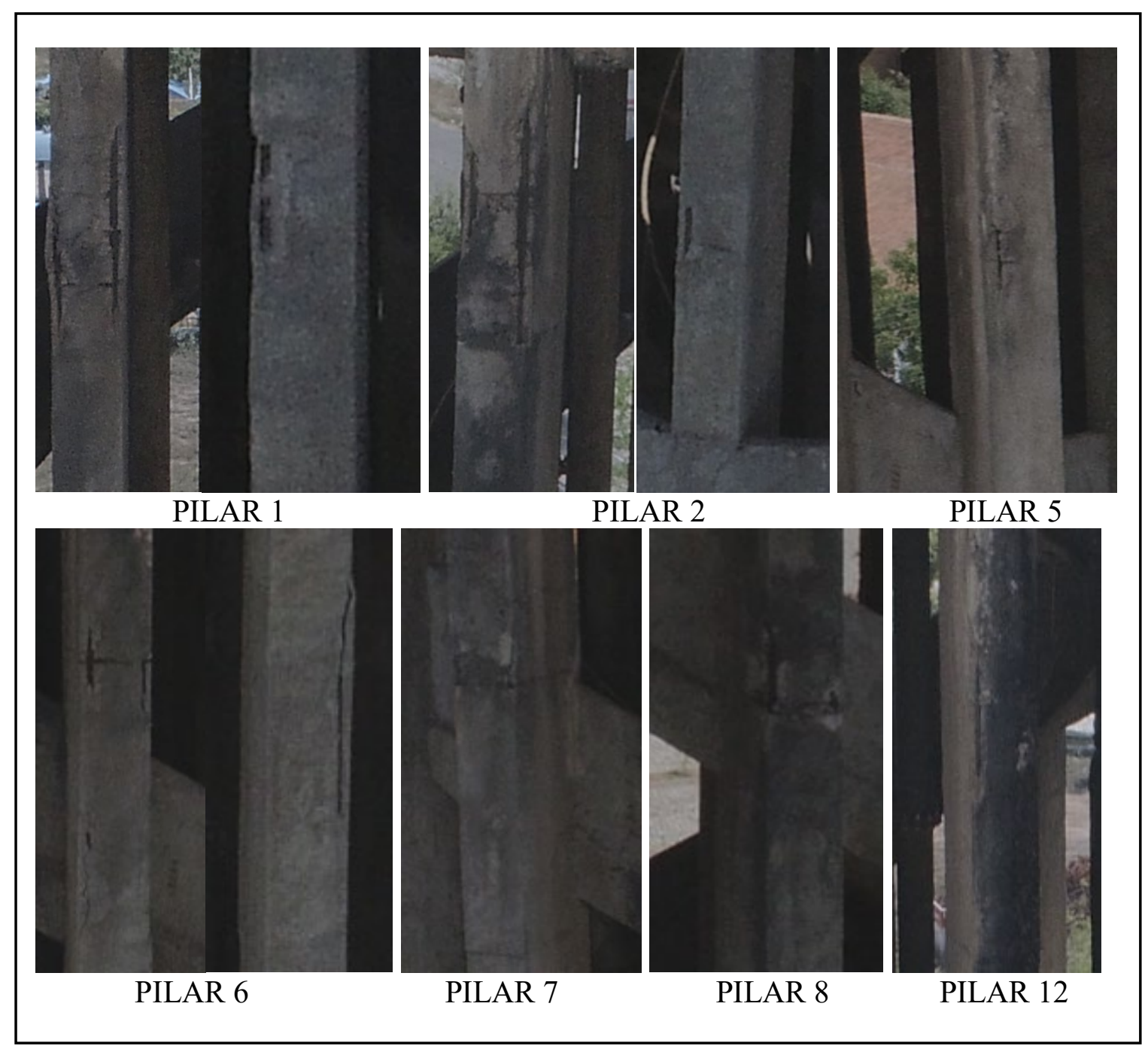

Figura 4. Análise de desplacamento. Fonte: Arquivo da pesquisa (2021).

Desplacamentos também foram localizados nas vigas de sustentação e nas lajes da base do reservatório. Nos mesmos, pode-se observar também exposição e oxidação das armaduras. Tais manifestações patológicas foram observadas nas estruturas entre os pilares: 1 e 2; 6 e 7; 9 e 10. Superiormente, foi observado também nas vigas dos pilares 3, 6 e 7. Pode ser analisado no mosaico da Figura 5.

Há sinais de lixiviação nas lajes de sustentação nos locais onde ocorre vazamento de água do reservatorio, observados no mosaico da Figura 6. 


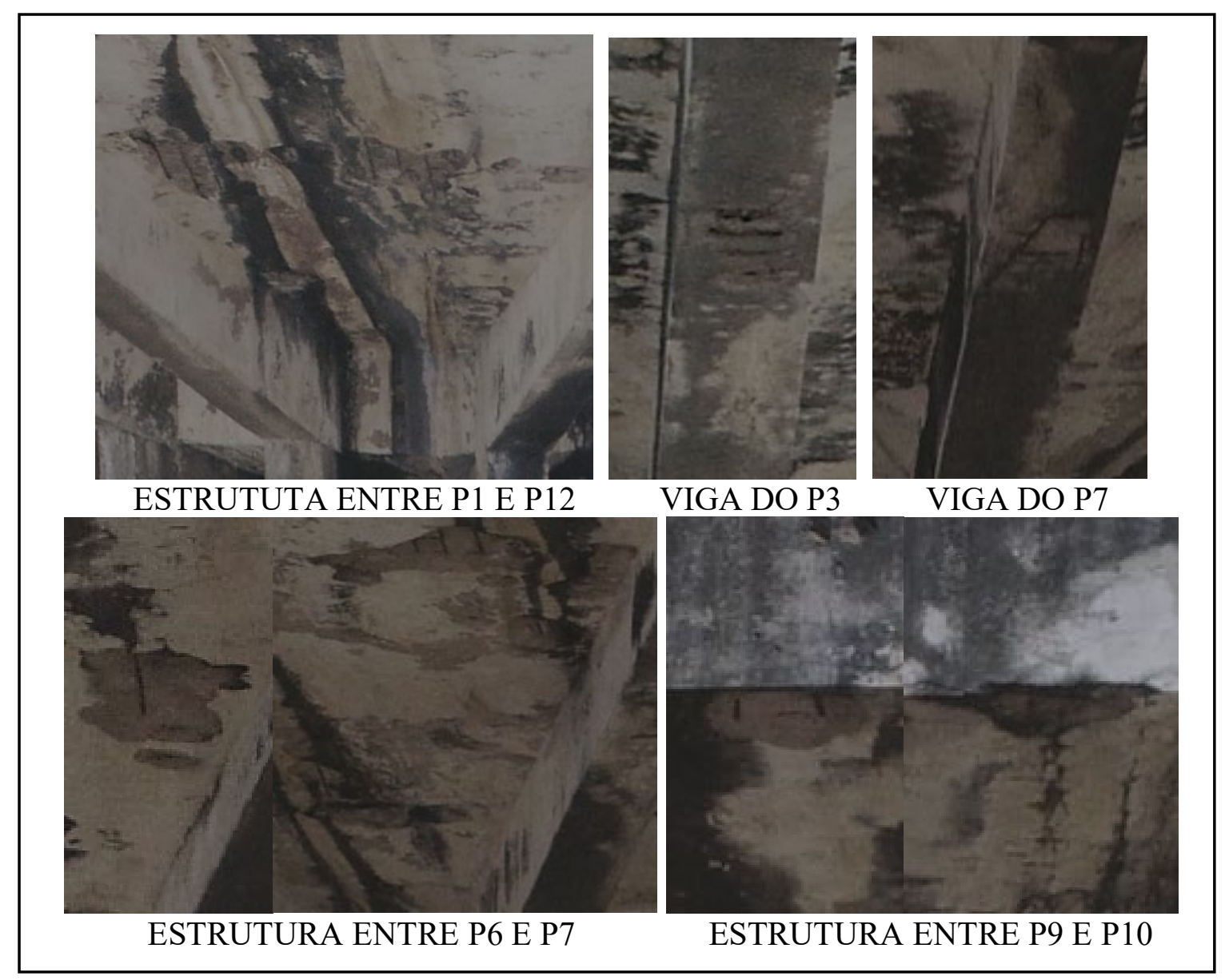

Figura 5. Análise de desplacamento. Fonte: Arquivo da pesquisa (2021).

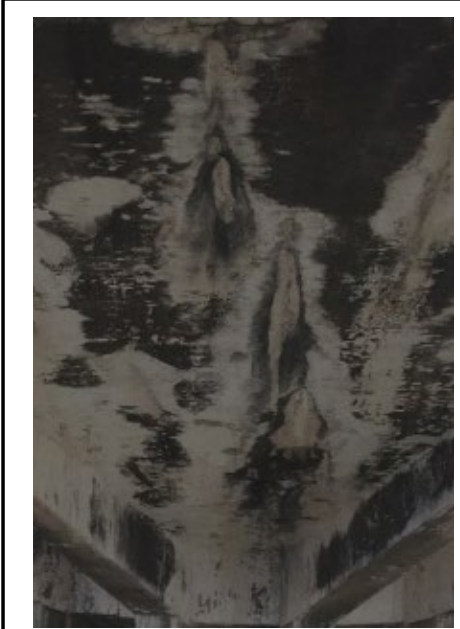

ESTRUTURA ENTRE

P3 E P4

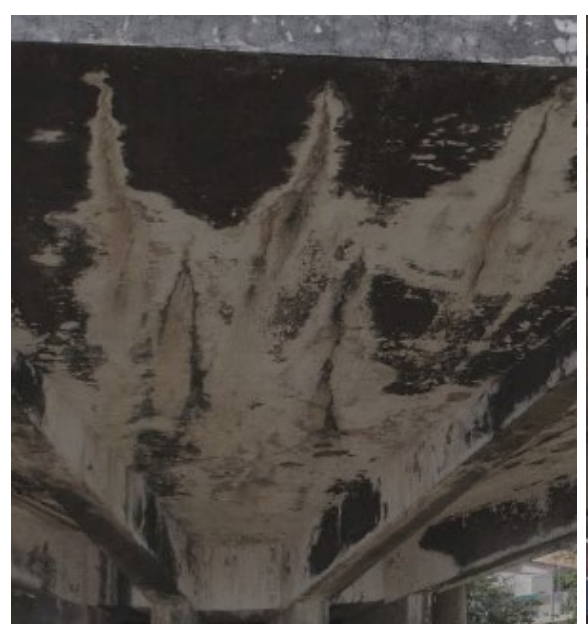

ESTRUTURA ENTRE

P5 E P6

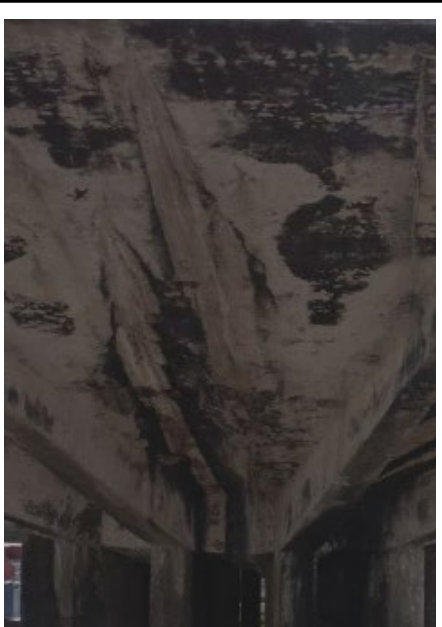

ESTRUTURA ENTRE P12 E P1

Figura 6: Análise de lixiviação. Fonte: Arquivo da pesquisa (2018).

$\mathrm{O}$ vazamento em grande volume de água também evidencia a presença de rachaduras. $\mathrm{O}$ vazamento com grande vazão (observado durante a investigação visual) não ocorre com trincas e fissuras (que não permitem entrada de água, ar ou luz). 
A partir da inspeção visual da obra, constatou-se diversas manifestações patológicas que são resultantes não só das condições do ambiente externo (exposto às forças naturais de sol e chuva), mas principalmente da falta de manutenção preventiva ou erros de projeto. O tamanho das exposições das armaduras encontradas e o grande vazamento de água do próprio reservatório observados sustentam o argumento de que a obra foi negligenciada durante muito tempo e ficou sem os cuidados de manutenção por tempo suficiente para que a patologia avançasse a um ponto crítico.

O vazamento é um problema não apenas ambiental, tendo visto que a companhia trabalha com a distribuição de um recurso valioso e escasso como a água, mas também, reflete um problema estrutural que pode ser interpretado como uma situação de pré-colapso. Conforme foi ignorado, a água não apenas acha o caminho pela rachadura, mas tem uma forte tendência a aumentar lentamente o tamanho da mesma.

Devido à exposição da estrutura aos numerosos processos de deterioração fazem-se necessários cuidados para preservar a funcionalidade da estrutura e a continuação de sua vida útil. Para tanto, adota-se uma proposta de intervenção imediata e manutenção eficiente, que inclua os procedimentos necessários ao bom estado da construção. Na edificação analisada, apenas o processo de manutenção é inadequado ou insuficiente para evitar a ocorrência de manifestações patológicas e provável ruína. Uma recuperação emergencial se faz necessária para evitar a inutilização e o colapso total da estrutura.

Apesar de outras análises serem necessárias, existem métodos indicados genericamente para as patologias cujas manifestações indicam. Primeiro, esvazia-se o reservatório, depois, com o auxílio de andaimes instalados para melhor alcance da estrutura, faz-se a remoção de todo o concreto disgregado utilizando martelete elétrico com ponteiro, por dentro e por fora. Analisase o nível da corrosão das barras, fazendo remoção da ferrugem e, onde for necessário por haver grande comprometimento da seção transversal, fazer a substituição por novas barras com emendas por transpasse. Aplica-se impermeabilizante anticorrosivo nas barras e realiza-se a nova concretagem utilizando forma e concreto graute. Impermeabiliza-se internamente o reservatório por meio da regullarização do substrato e aplicação de novo impermeabilizante. Promove-se a pintura da estrutura e coloca-se em operação novamente.

Apenas por meio da inspeção visual, não é possível apontar com plena certeza a possibilidade de recuperação da estrutura supracitada. De acordo com Cascudo (1994), alguns dos métodos mais usuais de recuperação são: remoção eletroquímica dos cloretos, controle do processo catódico e proteção catódica.

\section{CONCLUSÕES}

A metodologia de análise inicial por meio do uso de drone obteve sucesso pois indicou a condição emergencial em que se encontra a estrutura, fazendo com que se possa condenar o estado atual da estrutura sem demais análises que possam colocar em risco desnecessário a integridade do profissional de engenharia. Este se apresenta como principal ponto para a aplicação desta tecnologia como principal na análise de obras de difícil acesso.

As manifestações patológicas encontradas em maior quantidade na edificação em estudo foram: desplacamento da estrutura de concreto, exposição e oxidação de armaduras, presença de bolor, eflorescência e rachaduras.

Através da inspeção visual, contatou-se a presença de ferragens expostas e rachaduras nos pilares causados pelo desplacamento do concreto armado, assim como a umidade em excesso facilitando a ação de microrganismos responsáveis pela proliferação de fungo e bolor. É interessante ressaltar que as manifestações percebidas são oriundas, principalmente, da falta de manutenção preventiva ou erros de projeto. 
O presente artigo propôs adotar uma proposta de manutenção eficiente, cuja função é explanar procedimentos necessários a fim de garantir o bom estado da construção, tendo em vista que a estrutura necessita de uma recuperação emergencial para evitar a inutilização da estrutura. Constatou-se que existem nas literaturas processos que permitem a recuperação das estruturas observadas na construção. A inspeção visual não é suficiente para determinar qual o método mais adequado de recuperação, porém, a metodologia aplicada norteia procedimentos futuros de análise e correção das manifestações patológicas, provando a eficiência da adoção do Drone para inspeção de obras em altura.

\section{AGRADECIMIENTOS}

Agradeço ao Núcleo de Pesquisa e Extensão Acesso à Terra Urbanizada pelo incentivo à pesquisa, capacitação e pelas bolsas de pesquisa e extensão aos autores do presente artigo.

\section{REFERÊNCIAS}

ANDRADE, C. (1992), "Manual para diagnóstico de obras deterioradas por corrosão de armaduras”, Tradução de Antônio Carmona e Paulo Helene, São Paulo: PINI, p. 104.

Agência Nacional de Aviação Civil - ANAC. Disposições gerais sobre uso de Drones. Disponível em: $<$ http://www.anac.gov.br/assuntos/paginas-tematicas/drones $>$. Acesso em: 28 jul. 2018.

Bhonge, S. S., Dalwi, Pradeep, Kulkarni, J. K., Manjrekar, S. K. (2020), "Recomendações para reabilitação e proteção contra a corrosão de uma ponte metálica de 100 anos de idade (Durgadee) sobre um rio fortemente poluído perto de Mumbai, Índia", Revista ALCONPAT, 10 (2), pp. 259 - 273, DOI: http://dx.doi.org/10.21041/ra.v10i2.476

CASCUDO, Oswaldo. "O controle da corrosão de armaduras em concreto: inspeção e técnicas eletroquímicas”. Goiânia: Editora UFG, 1997. 237 p.

DJI Phantom 4 Pro. Top Drone. 2018. Disponível em: <https://www.topdrone.com.br/djiphantom-4-pro/p>. Acesso em: 05 jul. 2018.

FERNANDES, R. T. V., CABRAL, A. F., DANTAS, G. C. B., Tinoco, V. N. V., SILVEIRA, B. D. A., SOUSA JUNIOR, A. M. (2021), "Mapeamento de manifestações patológicas em pavimento asfáltico por meio de uso de drones", Revista ALCONPAT, 11 (1), pp. 61 - 72 , DOI: https://doi.org/10.21041/ra.v11i1.521

Melo, R.R.S. 2016. "Diretrizes para inspeção de segurança em canteiros de obra por meio de imageamento com Veículo Aéreo Não Tripulado (VANT)”. 160 f. Dissertação (Mestrado) Curso de Engenharia Civil, Universidade Federal da Bahia, Salvador, 2016.

QUEIROZ, Robson de Oliveira. "Patologias em fachadas construídas com revestimento de argamassa". 2007. 88 f. TCC (Graduação) - Curso de Engenharia Civil, Universidade Anhembi Morumbi, São Paulo, 2007. 
ROSCOE, M. T. "Patologia em revestimento cerâmico de fachadas". 2008. Monografia (Especialização em Construção Civil da Escola de Engenharia) - Universidade Federal de Minas Gerais, Belo Horizonte, 2008.

SOUZA, Vicente Custódio De. RIPPER, Thomaz. "Patologia, recuperação e reforços de estruturas de concreto". 1. ed. São Paulo: Pini, 1998. 